\section{Обоснование комплексного показателя оценки состояния лесовозного автомобиля}

\author{
В. М. Солнышков ${ }^{1}$ \\ Петрозаводский государственный университет
}

\begin{abstract}
АННОТАЦИЯ
Обосновывается комплексный показатель оценки работы лесотранспортного автомобиля, который используется в методике назначения периодичности технического обслуживания, учитывающей характеристики дорог (уклоны, радиусы переходных кривых, покрытие и др.), техническое состояние автопарка предприятия на настоящий момент.
\end{abstract}

Ключевые слова: лесотранспортные автомобили, техническое обслуживание, комплексный показатель, коэффициент корреляции.

\section{SUMMARY}

The complex factor of the serviceability estimation of timber truck is proved which is used to determine periodicity of the maintenance service, taking into account characteristics of roads (Inclinations, radiuses of transitive curves, a covering etc.), a technical condition of a motorvehicle pool of the enterprise at present moment.

Keywords: timber truck, maintenance service, integrated measure, factor of correlation.

Успешное решение задачи повышения качества технической эксплуатации автопоездов требует создания новой методики оценивания и оптимизации показателей качества эксплуатации лесовозной техники. Важнейшим этапом при создании методики определения периодичности технического обслуживания (ТО) с применением геоинформационных систем является разработка обобщенного показателя надежности автомобиля.

Данная техническая задача является многоцелевой, т. к. при выборе наилучшего варианта приходится учитывать много различных требований, предъявляемых к машине и условиям, в которых она эксплуатируется. В действительности, если рассматривать лесовозный автомобиль, данная задача осложняется тем, что имеют место категории процессов, различные по скорости их протекания $[3,5,6]$. На машину действуют и быстропротекающие процессы, и процессы средней скорости, и медленные процессы. Кроме того, каждая машина характеризуется несколькими выходными параметрами. При этом за счет ремонта и технического обслуживания могут частично или полностью восстанавливаться утраченные характеристики. Рассмотрим с указанных позиций общую схему потери

\footnotetext{
${ }^{1}$ Автор - аспирант кафедры тяговых машин (C) В. М. Солнышков, 2003
}

машиной работоспособности, т. е. такую модель отказов, которая учитывает процессы разной скорости.

Пусть $X$ - один из параметров, характеризующих работоспособность машины (мощность, к.п.д., производительность и др.[3]), а $\delta$ - та часть, на которую может быть снижен (ухудшен) параметр без выхода его за допустимые пределы, т. е. $\delta$ - это запас на «износ» (в широком смысле), это те допустимые погрешности в работе машины, которые не приводят к нарушению ее работоспособности. Процесс изменения параметра $X$ на величину $\delta$ с течением времени $\mathrm{t}$, т. е. процесс изменения состояния машины, и представляет собой общую картину постепенной потери машиной работоспособности, происходящей при ее эксплуатации. Для выбора $X$ воспользуемся процедурами априорного типа, в которых делается явное или неявное предположение, что вся информация, позволяющая определить наилучшее решение, скрыта в формальной модели задачи и, следовательно, с помощью некоторых преобразований может быть из этой формальной модели извлечена и использована, т. е. считается, что множеств альтернатив $\mathrm{U}$ и целевых функций $\mathrm{X}_{1}(\mathrm{u}), \mathrm{X}_{2}(\mathrm{u}), \ldots$ вполне достаточно для объективного, не зависящего от отсутствующих в данной модели факторов определения оптимального решения $[2,3]$.

Одним из методов принятия решений является метод главной компоненты, который заключается в произвольном выборе одного из компонентов в качестве главного, по которому производится оптимизация и выбирается решение. При этом остальные компоненты переводятся в разряд ограничений.

Этот метод прост, нагляден и часто применяется в практике, однако принципиальным его недостатком является произвол в выборе главного критерия. Когда решаются технологические задачи лесного производства принято использовать в качестве главной компоненты производительность [2].

Обобщенная оценка технического состояния автомобиля в методике определения периодичности ТО осуществляется с помощью комплексного средневзвешенного арифметического показателя, позволяющего суммировать относительные показатели отдельных элементарных участков, на которые разбивается маршрут движения. Полезный эффект от эксплуатации лесотранспортной машины выражается ее производительностью. Одно из основных свойств лесовозного автомобиля - надежность, которая, в свою очередь, характеризуется рядом параметров. Одним из самых важных параметров является безотказность, его показателями являются: вероятность безотказной работы, интенсивность отказов, средняя наработка на отказ, средняя наработка до отказа и др. [1].

Для установления связи между средней наработкой на отказ и полезным эффектом от эксплуатации лесовозного автомобиля был выполнен анализ влияния 
средней наработки на отказ на производительность автомобиля. Анализ производился на примере парка лесовозных автомобилей предприятия ОАО «Запкареллес». Лесозаготовительное предприятие ОАО «Запкареллес» находится на территории Суоярвского района. Суоярвский район расположен на юго-западе Республики Карелия. Общая протяженность государственной границы района с Финляндией составляет 120 км. Расстояние от города Суоярви до таможенного перехода Вяртсиля равно 135 км, до города Петрозаводска - 135 км, до Санкт-Петербурга - 539 км, до Москвы - 1200 км. ОАО «Запкареллес» - одна из крупнейших в России и ведущая в Республике Карелия комплексная лесозаготовительная и деревообрабатывающая компания. Предприятие арендует у государства около 800 тыс. га участков лесного фонда. Основные направления деятельности: лесозаготовка; лесопиление и деревообработка; лесохозяйственные работы; строительство лесовозных дорог круглогодового действия; реконструкция и капитальное строительство промышленных объектов; проектноизыскательные работы.

Производственная структура предприятия включает 6 лесозаготовительных пунктов, в том числе Лахколамбский, Питсийокский, Вегурский, Суоякский, Лоймольский и Райконкосский, лесопильный завод в поселке Найстельярви, ремонтно-механический завод, строительный и транспортный цеха. На предприятии работает 2662 человека, в том числе на лесозаготовке 1706 человек.

За 2000 год было произведено товарной продукции на 460379 тыс. руб., вывозка древесины составила 629 тыс. кбм., в 2001 году произведено товарной продукции на 436320 тыс. руб., вывозка древесины составила 600 тыс. кбм. Автомобильный пар лесовозных машин насчитывает 64 шт. (самый большой в Карелии). Основу статистических данных об эксплуатации парка лесовозных автомобилей составляют данные за 2000 и 2001 гг. В результате была получена следующая зависимость: $y=58.711 \cdot e^{0.001 \cdot x}$, график которой показан на рис. 1.

Данная зависимость справедлива только для предприятия ОАО «Запкареллес» и автомобилей, которые эксплуатируются в условиях данного предприятия. Насколько хорошо полученное уравнение описывает отклик как функцию факторов средней наработки от производительности, характеризует множественный коэффициент корреляции $r$, который определяется по следующей формуле:

$$
\begin{gathered}
r=1-\frac{\left(1-R^{2}\right) \cdot(n-1)}{n-k}, \\
\text { где } R^{2}=\frac{\sum_{n=1}^{n}(y-\bar{y})^{2}}{\sum_{n-1}^{n}\left(y_{n}-\bar{y}\right)}-\text { средние значения выборки, } \\
\mathrm{k} \text { - количество переменных в моделях, }
\end{gathered}
$$

$$
\begin{aligned}
& \bar{y}=\frac{1}{n} \cdot \sum_{i=1}^{n} y_{i}-\text { средние значения выборки, } \\
& \text { у - значения по модели, } \\
& \mathrm{y}_{\mathrm{n}}-\text { значения по выборке. }
\end{aligned}
$$

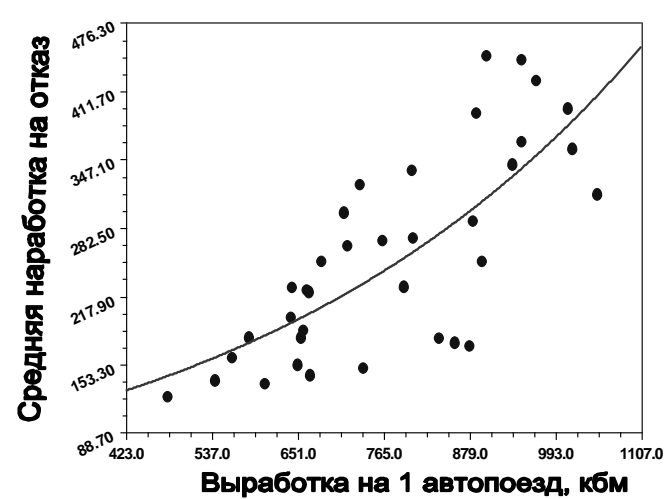

Рис. 1. Зависимость средней наработки на отказ от производительности автопоезда

После подстановки данных были получены следующие значения: корреляционный коэффициент $r=$ 0,752 , коэффициенты равны следующим значениям $a=58,711 ; b=0,001$.

Чем ближе $r$ к единице, тем с большей вероятностью можно сказать, что наше уравнение описывает отклик как функцию факторов средней наработки от производительности.

Таким образом, после определения зависимости между средней наработкой и производительностью можно переходить к обобщению оценки технического состояния автомобиля в методике определения периодичности ТО.

\section{СПИСОК ЛИТЕРАТУРЫ}

1. Андреев В. Н. Надежность лесных машин и оборудования: Учебное пособие / ЛТА. Л., 1991. $152 \mathrm{c}$.

2. Андреев В. Н., Герасимов Ю. Ю. Принятие оптимальных решений: теория и применение в лесном комплексе. Йоэнсуу: Изд-во университета Йоэнсуу, 1999. 200 с.

3. Проников А. С. Надежность машин. М.: Машиностроение, 1978. 592 с., ил.

4. Ахназарова С. Л., Кафаров В. В. Оптимизация эксперимента в химии и технической технологии: Учеб. пособие для химикотехнологических вузов. М.: Высш. школа, 1978. 319c., ил.

5. Хазов Б. Ф., Дидусев Б. А. Справочник по расчету надежности машин на стадии проектирования. М.: Машиностроение. 1986. 224 с., ил.

6. Kapur K. C., Lamberson L. R. Reliability in Engineering Design / Department of Industrial Engineering and Operations Research Wayne State University Detroit. Michigan 48202. 